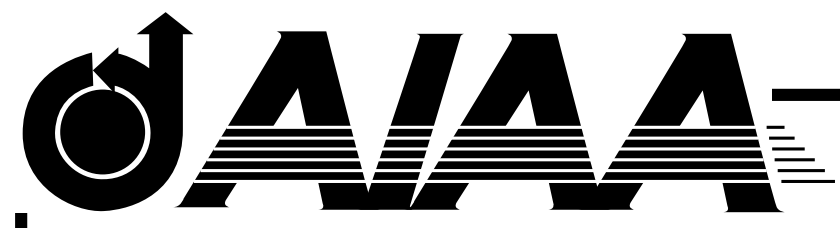 \\ AIAA 99-3558 \\ X-33 Experimental Aeroheating at Mach 6 Using Phosphor Thermography
}

T. J. Horvath, S. A. Berry, B. R. Hollis,

D. S. Liechty, H. H. Hamilton II, and N. R. Merski

NASA Langley Research Center

Hampton, Virginia 23681

\section{3rd Thermophysics Conference 28 June - 1 July, 1999 / Norfolk, VA}




\title{
X-33 EXPERIMENTAL AEROHEATING AT MACH 6 USING PHOSPHOR THERMOGRAPHY
}

\author{
Thomas J. Horvath*, Scott A. Berry", Brian R. Hollis ${ }^{* \dagger}$, Derek S. Liechty, H. Harris Hamilton II $^{* \dagger}$, \\ and N. Ronald Merski* ${ }^{*}$ \\ Abstract
}

The goal of the NASA Reusable Launch Vehicle (RLV) technology program is to mature and demonstrate essential, cost effective technologies for next generation launch systems. The X-33 flight vehicle presently being developed by Lockheed Martin is an experimental Single Stage to Orbit (SSTO) demonstrator that seeks to validate critical technologies and insure applicability to a full scale RLV. As with the design of any hypersonic vehicle, the aeroheating environment is an important issue and one of the key technologies being demonstrated on X-33 is an advanced metallic Thermal Protection System (TPS). As part of the development of this TPS system, the X-33 aeroheating environment is being defined through conceptual analysis, ground based testing, and computational fluid dynamics. This report provides an overview of the hypersonic aeroheating wind tunnel program conducted at the NASA Langley Research Center in support of the ground based testing activities. Global surface heat transfer images, surface streamline patterns, and shock shapes were measured on 0.013 scale (10-in.) ceramic models of the proposed X-33 configuration in Mach 6 air. The test parametrics include angles of attack from -5 to 40 degs, unit Reynolds numbers from $1 \times 10^{6}$ to $8 \times 10^{6} / f t$, and body flap deflections of 0,10 , and 20 deg. Experimental and computational results indicate the presence of shock/shock interactions that produced localized heating on the deflected flaps and boundary layer transition on the canted fins. Comparisons of the experimental data to laminar and turbulent predictions were performed. Laminar windward heating data from the wind tunnel was extrapolated to flight surface temperatures and generally compared to within $50 \mathrm{deg} F$ of flight prediction along the centerline. When coupled with the phosphor technique, this rapid extrapolation method would serve as an invaluable TPS design tool.

\section{Nomenclature}

$\mathrm{h}$ heat transfer coeff. $\left(\mathrm{lbm} / \mathrm{ft}^{2}-\mathrm{sec}\right), \mathrm{g}^{\mathrm{N}} /\left(\mathrm{H}_{\mathrm{aw}}-\mathrm{H}_{\mathrm{w}}\right)$ where $\mathrm{H}_{\mathrm{aw}}=\mathrm{H}_{\mathrm{t}, 2}$

$\mathrm{H}$ enthalpy (BTU/lbm)

M Mach number

$\mathrm{P}$ pressure, psia

q. heat transfer rate $\left(\mathrm{BTU} / \mathrm{ft}^{2}-\mathrm{sec}\right)$

$\mathrm{r}$ radius (in.)

t time (sec)

Re unit Reynolds number $(1 / \mathrm{ft})$

$\mathrm{T}$ temperature $\left({ }^{\circ} \mathrm{R}\right)$

$\mathrm{u} \quad$ velocity $(\mathrm{ft} / \mathrm{sec})$

$\mathrm{x} \quad$ axial distance from origin (in.)

y lateral distance from origin (in.)

$\mathrm{z} \quad$ vertical distance from origin (in.)

$\alpha \quad$ angle of attack (deg)

$\delta \quad$ control surface deflection (deg)

\section{Subscripts}

aw adiabatic wall

BF body flap

FR Fay-Riddell, stagnation-point, reference heating condition

\footnotetext{
* Aerospace Technologist, Aerothermodynamics Branch, Aeroand Gas-Dynamics Division, NASA Langley Research Center, Hampton, VA 23681.

$\dagger$ Member, AIAA

Copyright (C1999 by the American Institute of Aeronautics and Astronautics, Inc. No copyright is asserted in the United States under Title 17, U.S. Code. The U.S. Government has a royaltyfree license to exercise all rights under the copyright claimed herein for government purposes. All other rights are reserved by the copyright owner.
}

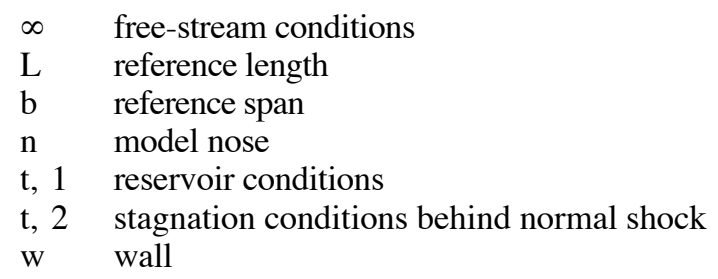

\section{Introduction}

The Access to Space Study ${ }^{1}$ conducted by NASA recommended the development of a fully reusable launch vehicle (RLV) ${ }^{2,3,4}$ to provide a next-generation launch capability at greatly reduced cost. This led to the RLV/X-33 technology program, an industry-led effort in partnership with NASA. The primary goal of the RLV/X-33 technology program is to enable significant reductions in the cost of access to space. The full-scale RLV system must be lightweight enough to achieve orbit and deliver a payload in a cost-effective manner. As part of the RLV program, the $\mathrm{X}-33$ is envisioned as a sub-scale rocket technology demonstrator for a Single-Stage-To-Orbit (SSTO) RLV. The proposed X-33 vehicle is intended to demonstrate key design and operational aspects of a commercially viable system SSTO RLV rocket. Following a Phase I industry competition for X-33, Lockheed Martin's lifting body concept was selected by NASA and Lockheed was awarded a Phase II contract (July 1996) to pursue construction of the flight vehicle. Lockheed's current lifting body design, Fig. 1, shown in the dimensioned sketch at model scale, represents a one-half scale RLV and incorporates symmetric canted fins, twin vertical tails, two body flaps located at the rear of the fuselage 
for aerodynamic control, and is powered by a linear aero-spike engine 5 .

As part of the Industry/Government partnership, NASA Langley Research Center (LaRC) has been tasked with providing surface heating data, including transition criteria, to Lockheed Martin in support of X-33 aerothermodynamic development and design. To meet the objectives outlined in the tasks, a synergistic experimental/computational approach was utilized. Results from early Phase II wind tunnel heating measurements were compared to laminar and turbulent CFD computations ${ }^{6}$. Flight peak heating rates over the $\mathrm{X}-33$ were then predicted with both an "engineering" code and a Navier-Stokes solver. The early data set was also used to formulate and support the use of $\operatorname{Re}_{\theta} / \mathrm{M}_{\mathrm{e}}$ criteria to predict transition onset for $\mathrm{X}-33^{7}$. Since the time of these publications, additional heating tests have been completed which supplemented the original database and accommodated design changes to the vehicle outer mold lines. Key Phase II experimental and computational aeroheating results are presented in this reference and in two companion papers by Berry et $\mathrm{al}^{8}$ and Hollis ${ }^{9}$ et al. An extensive testing effort was made to examine the effects of both discrete roughness and distributed roughness (in the form of a simulated array of thermally bowed metallic TPS panels) on transition. The sensitivity of X-33 boundary layer transition to this "wavy wall" and the validity of the discrete roughness defined $\mathrm{Re}_{\theta} / \mathrm{M}_{\mathrm{e}}$ transition criteria off vehicle centerline have been investigated ${ }^{8}$. Additional Navier Stokes computations were performed and detailed comparisons with the more recent wind tunnel data have been made to validate computational techniques used in predicting complex threedimensional flow-fields ${ }^{9}$. The experimental results were obtained in the LaRC Aerothermodynamic Facilities Complex ${ }^{10}$. Over 1100 tunnel runs from sixteen different entries in two facilities have been completed since Aug 1996. Table 1 provides a list of all the wind tunnel tests that have been completed to date in support of X-33 aeroheating since the Phase II down-select.

The purpose of this paper is to update and present an overview of the most current experimental measurements to characterize the X-33 windward and leeward aeroheating environments, and will focus on the heating associated with a nominally smooth surface. The wind tunnel data in this report was obtained from the NASA LaRC 20-Inch Mach 6 Air Tunnel. In terms of Mach and Reynolds number simulation, an early X-33 flight trajectory (9d-3) considered by Lockheed Martin (Fig. 2) indicates that the 63-ft long flight vehicle would experience a length Reynolds number $\left(\operatorname{Re}_{\mathrm{L}}\right)$, between 4 and 8 million at a freestream Mach number of 6 . This range of length Reynolds number can be produced in the LaRC 20-Inch Mach 6 Tunnel with an appropriately sized model. A $\mathrm{Re}_{\mathrm{L}}$ range of 0.4 to 6.7 million is achieved in this tunnel with a 10 -in model length. The current flight trajectory from Edwards AFB into Michael AFB has been modified from the preliminary trajectory (9d-3) shown and would place vehicle peak heating during ascent near Mach 9 at $\alpha=13$ deg and during descent near Mach 7 at $\alpha=32$ deg.

Test techniques that were utilized during these tests include thermographic phosphors, which provides global surface heating images; oil-flow, which provides surface streamline information; and schlieren, which provides shock system details. Parametrics included in these tests at Mach 6 were a large range of angle of attack to cover ascent and descent conditions $(-5<\alpha<40$ deg. $)$, unit Reynolds number ( $\mathrm{Re} / \mathrm{ft}$ between 1 and 8 million), and body flap deflections $\left(\delta_{\mathrm{BF}},=0,10\right.$, and $\left.20 \mathrm{deg}\right)$. Emphasis will be placed on the body flap surface heating augmentation due to deflection. Sample comparisons with CFD predictions (details provided, ref. 9) are included and are used to assess the state of the windward surface boundary layer. Extrapolation and comparison of laminar wind tunnel heating measurement to flight surface temperature predictions are made.

\section{X-33 Body Shape Evolution and Description}

The design of the Lockheed Martin X-33 lifting body that emerged from the Phase I competition drew upon a synthesis of work performed by the U.S. government and industry over the last few decades ${ }^{11,12}$. The X-33 body resembled a blunted slab with a delta shaped planform. Two body flaps trailed from the lower surface outboard of the base mounted linear aero-spike engine. These flaps, along with a pair of canted fins and a single vertical tail would be employed for aerodynamic control. Aerodynamic wind tunnel tests conducted in government labs (NASA LaRC ${ }^{13,14}$, NASA MSFC ${ }^{12}$ ), and commercial facilities continued after Phase I down-select with the goal of optimizing aerodynamic performance across the speed range. Although the basic lifting body shape has been maintained throughout the development, changes to the vehicle have occurred as the aero database matured. In the past, aeroheating information has significantly lagged behind aerodynamics due to model and instrumentation complexities associated with aerothermodynamic testing. The timeframe of the X-33 program coupled with the recent development of the two-color global phosphor thermography technique ${ }^{15-17}$ presented NASA Langley the first opportunity to conduct an aerothermodynamic screening/trade in parallel with aerodynamic development.

Phase II aerodynamic optimization studies 
produced a series of X-33 configurations with outer mold line (OML) changes of sufficient significance to warrant several aeroheating assessment/trade studies. The configuration that emerged from the Phase I down-select and was used in the early part of Phase II heating tests was referred to in the aeroheating community as the D-loft (603B1001D) - with the industry configuration designation ${ }^{18}$ shown in parenthesis. The subsequent configuration OML, the F loft Rev-C (604B0002C), differed from the D-loft in that it had twin vertical tails and incorporated some modifications which changed the nose shape slightly and the base region (in the vicinity of the engine). The nosecap changes were made to simplify the construction of the metallic TPS panels. Aerodynamic improvements to this vehicle shape resulted in F loft Rev-F (604B0002F), as shown in Fig.1. It has the same forebody shape as F loft Rev$\mathrm{C}$, but the dihedral of the 0012-64 airfoil canted fins was lowered from 37-deg to 20-deg (to improve pitchtrim characteristics across the speed range). At the same time, the fin incidence was lowered from -6.57 to $-8.57 \mathrm{deg}$. Finally, the size of the body flaps and vertical tails was increased (to improve trim characteristics and low-speed lateral-directional stability, respectively). The last OML iteration that has undergone heating tests at $\mathrm{LaRC}$ is known as $\mathrm{F}$ loft Rev-G (604B0002G). Small protrusions on the leeward surface near the vertical tails were added to accommodate internal structural changes and the canted fin body fillet was modified. While other more recent systematic configuration changes have resulted in minor vehicle OML modifications, these changes were not significant enough to warrant construction of new models and additional wind tunnel testing.

\section{Experimental Methods}

\section{$\underline{\text { Models }}$}

A majority of the cast ceramic aeroheating models are a 10 -inch long 0.0132 -scale representation of the proposed 63-ft long (from nose to the end of the aerospike engine base) X-33 F loft Rev-F (604B0002F) flight vehicle. In addition to configuration assessment of the X-33 OML revisions ( $\mathrm{L}=10$-in.), an attempt to qualitatively characterize the influence of model size on tunnel partial blockage effects was made. This was accomplished by limited testing of two smaller scale Rev F models ( $\mathrm{L}=5.7$-in. and $\mathrm{L}=6.5$-in.).

Over 70 ceramic models were fabricated in support of the LaRC X-33 aerothermodynamic program, all of which share a common construction technique. A rapid prototyping technique was first used to build a resin stereolithography (SLA) model with various, detachable body flaps on both the port and starboard region of the base of the vehicle. The SLA resin model was then assembled with the desired control surface settings and served as a pattern to construct molds from which the cast ceramic model configurations were made. A magnesia ceramic was used to backfill the ceramic shells, thus providing strength and support to the sting support structure.

A photograph of three 0.0132 scale (10-in.) Rev-F model configurations with the various body flap deflections are shown in Fig.3. Typically, two casts of each configuration were made; the primary being immediately prepared for testing and the backup shell held in reserve, in case of problems with the primary. In order to obtain accurate heat transfer data with the phosphor technique, the models are cast with a material with low thermal diffusivity and well defined, uniform, isotropic thermal properties. The phosphor coatings typically do not require refurbishment between runs in the wind tunnel and have been measured to be approximately 0.001 inches thick. Details concerning the model fabrication technique and phosphor coating can be found in refs.19 and 20. Fiducial marks were placed on the model surface to assist in determining spatial locations accurately.

Once the phosphor testing was completed, the untested backup models were prepared (spray-coated and kiln fired with a thin black glazing) for use as oilflow and schlieren models.

\section{Facility Description}

The X-33 aeroheating test series was conducted in two hypersonic blowdown facilities that are part of the LaRC Aerothermodynamic Facilities Complex. Detailed descriptions of the facilities within the complex can be found in ref. 10. A brief description of the 20-Inch Mach 6 Tunnel follows, since a majority of the tests were in this facility.

The 20-Inch Mach 6 Tunnel uses heated, dried, and filtered air as the test gas. Typical operating conditions for the tunnel are: stagnation pressures ranging from 30 to 500 psia; stagnation temperatures from 760-deg to 1000-degR; and freestream unit Reynolds numbers from 0.5 to 8 million per foot. A two-dimensional, contoured nozzle is used to provide nominal freestream Mach numbers from 5.8 to 6.1. The test section is 20.5 by 20 inches; the nozzle throat is 0.399 by 20.5 -inch. A bottom-mounted model injection system can insert models from a sheltered position to the tunnel centerline in less than 0.5 -sec. Run times up to 15 minutes are possible with this facility, although for the current heat transfer and flow visualization tests, the model residence time in the flow is limited to only a few seconds. Flow conditions were determined from the measured reservoir pressure and temperature and the measured pitot pressure at the test section.

\section{Test Conditions and Setup}

Nominal reservoir and corresponding free stream flow conditions for the 20-Inch Mach 6 
Tunnel is presented in ref. 20. The freestream properties were determined from the measured reservoir pressure and temperature and the measured pitot pressure at the test section. The reservoir pressure $\mathrm{pt}_{\mathrm{t}, 1}$ was measured with two silicon sensors having a full scale rating of 150 psia or 500 psia, depending on the operating condition of the tunnel. The reservoir temperature $T_{t, 1}$ was measured with two iron-constantan thermocouples inserted through the wall of the settling chamber. Test section wall static and pitot pressures were monitored and compared to tunnel empty conditions to assess if model blockage effects existed. No significant differences in pitot pressure were measured and it was concluded that significant blockage did not exist (up to 40 deg angle of attack, the limit of the tests). The ratio of projected model frontal area to tunnel cross sectional area for the present test was 0.1 (@L=10in., $\alpha=40 \mathrm{deg}$ ).

All models were supported by a base mounted cylindrical sting with the exception of two models ( $\mathrm{L}=6.5$-in and 5.7-in..) which were blade supported from the leeside to assess support interference effects. Details of the X-33 ceramic heat transfer model installation in the NASA LaRC 20-Inch Mach 6 Air Tunnel can be found in ref 20. The various model configurations were pitched through angle of attack in increments of $5 \mathrm{deg}$. A limited number of runs were made at incidence angles outside these increments to match conditions at points in the X-33 trajectory of interest to the aerodynamic community. Sideslip was held fixed at 0 deg with the exception of the tests conducted in the 20-Inch Mach $6 \mathrm{CF}_{4}$ Tunnel with a sideslip angle of $4 \mathrm{deg}$.

\section{Test Techniques}

The rapid advances in image processing technology which have occurred in recent years have made digital optical measurement techniques practical in the wind tunnel. One such optical acquisition method is two-color relative-intensity phosphor thermography ${ }^{15-17}$ which is currently being applied to aeroheating tests in the hypersonic wind tunnels of NASA Langley Research Center. ${ }^{21-23}$ With this technique, ceramic wind tunnel models are fabricated and coated with phosphors that fluoresce in two regions of the visible spectrum when illuminated with ultraviolet light. The fluorescence intensity is dependent upon the amount of incident ultraviolet light and the local surface temperature of the phosphors. By acquiring fluorescence intensity images with a color video camera of an illuminated phosphor model exposed to flow in a wind tunnel, surface temperature mappings can be calculated on the portions of the model that are in the field of view of the camera. A temperature calibration of the system conducted prior to the study provides the look-up tables that are used to convert the ratio of the green and red intensity images to global temperature mappings. With temperature images acquired at different times in a wind tunnel run, global heat transfer images are computed assuming onedimensional semi-infinite heat conduction. The primary advantage of the phosphor technique is the global resolution of the quantitative heat transfer data. Such data can be used to identify the heating footprint of complex, three-dimensional flow phenomena (e.g., transition fronts, turbulent wedges, boundary layer vortices, etc.) that are extremely difficult to resolve by discrete measurement techniques. Because models are fabricated and instrumented more rapidly and economically, global phosphor thermography has largely replaced discrete heating instrumentation in Langley's AFC.

Flow visualization techniques, in the form of schlieren and oil-flow, were used to complement the surface heating tests. The LaRC 20-Inch Mach 6 Tunnel is equipped with a pulsed white-light, Zpattern, single-pass schlieren system with a field of view encompassing the entire 20 -in test core. Images were recorded on a high-resolution digital camera, enhanced with commercial software and electronically placed into this report. Surface streamline patterns were obtained using the oil-flow technique. Backup ceramic models were spray-painted black to enhance contrast with the white pigmented oils used to trace streamline movement. A thin basecoat of clear silicon oil was first applied to the surface, and then a mist of pinhead-sized pigmented-oil drops was applied onto the surface. After the model surface was prepared, the model was injected into the airstream and the development of the surface streamlines was recorded with a conventional video camera. The model was retracted immediately following flow establishment and formation of streamline patterns, and post-run digital photographs were taken.

Data Reduction and Uncertainty

A 16-bit analog-to-digital facility acquisition system acquired flow condition data on all channels at a rate of 20 samples per second. Measured values of $\mathrm{P}_{\mathrm{t}, 1 \text { and }} \mathrm{T}_{\mathrm{t}, 1}$ are believed to be accurate to within \pm 2 percent. Heating rates were calculated from the global surface temperature measurements using onedimensional semi-infinite solid heat-conduction equations, as discussed in detail in ref. 17. As discussed in this reference, the accuracy of the phosphor system measurement is dependent on the temperature rise on the surface of the model. For the windward side heating measurements, the phosphor system measurement accuracy is believed to be better than $\pm 8 \%$, and the overall experimental uncertainty of the heating data due to all factors is estimated to be $\pm 15 \%$. In areas on the model where the surface 
temperature rise is only a few degrees (i.e. leeside or aerospike engine), the estimated overall uncertainty increases to at least $\pm 25 \%$. Repeatability for the normalized windward centerline (laminar) heat transfer measurements was found to be generally better than $\pm 4 \%$.

\section{Prediction Method}

X-33 Rev-F flow field computations for selected angles-of-attack and test conditions were performed using the General Aerodynamic Simulation Program (GASP) $\operatorname{code}^{24}$ developed by Aerosoft Inc. GASP is a three-dimensional, finite-volume code which incorporates numerous options for fluxsplitting methods, thermochemical and turbulence models and time-integration schemes. Predicted heating from GASP has been validated against flight data obtained from the Shuttle Orbiter. ${ }^{25}$ In the present work, a perfect gas air model was employed with a Jacobi time integration scheme. Full viscous terms were retained for all three directions. A thirdorder Roe flux splitting scheme was used in the normal direction to accurately capture shock and boundary layer gradients and third-order van Leer flux splitting was used in the streamwise and circumferential directions to promote stability. All cases were treated as either fully laminar or turbulent (the turbulent computations were performed using a modified algebraic Baldwin-Lomax model as discussed in ref. 9).

Grid description, sensitivity studies, turbulence model, and further details regarding the computational solutions presented in this report may be found in ref. 9.

\section{Results and Discussion}

\section{Preface}

The X-33 aeroheating results presented in this paper are organized around specific locations on the vehicle such as body flap, canted fin, etc. Presented in Fig. 4 is a sketch of the X-33 windward surface detailing the various nomenclature and flow features that will be referred to in the discussions. Flow visualization in the form of Schlieren and surface oil flows are used to assist in the analysis of the experimentally measured surface heating. The discussion of results will highlight some of the more relevant conclusions to date; a more complete presentation of flow visualization observations can be found in ref. 20.

Heating distributions are presented in terms of the ratio of enthalpy based heat-transfer coefficients $\mathrm{h} / \mathrm{h}_{\mathrm{FR}}$, where $\mathrm{h}_{\mathrm{FR}}$ corresponds to the Fay and Riddell ${ }^{26}$ stagnation-point heating to a sphere with radius equal to the wind tunnel model nose $\left(r_{n}=0.629\right.$-in for the 0.0132 scale 10 -in long model). A color bar having a maximum value of $\mathrm{h} / \mathrm{h}_{\mathrm{FR}}=1$ was selected for data presentation (except where noted) to maintain consistency when viewing or comparing the images. On the contour scale, the colors tending towards red indicate areas of higher heating (temperatures) while the colors towards blue represent areas of lower heating. In areas where the local heating exceeds the stagnation point reference value $\left(\mathrm{h} / \mathrm{h}_{\mathrm{FR}}>1\right)$, such as the deflected body flaps or fin leading edges, a gray "overscale" will be evident.

\section{Windward Fuselage}

The global effect of Reynolds number on the windward surface heating at Mach 6, $\alpha=40$ and 20 deg, and $\delta_{\mathrm{BF}}=20 \mathrm{deg}$ is shown in Figs. 5a-d and 6a-d, respectively. These two incident angles were selected to illustrate the distinctly different global heating patterns found on the windward surface near the model base. In order to understand the nature of this elevated heating, windward centerline heating distributions at $\alpha=40$ deg over a range of Reynolds numbers are compared with laminar and turbulent prediction in Fig. 7. Comparisons to laminar and turbulent predictions at other angles of attack can be found in refs. 8 and 9. At the highest Reynolds numbers tested, the experimental heating distributions reveal a departure from the laminar prediction near $\mathrm{X} / \mathrm{L}=0.4$. This suggests the boundary layer is transitioning to a turbulent state (for these test results, the model surface was considered smooth and transition was not forced via applied discrete roughness). Thus, it is reasonable to hypothesize that the progression of heating images in Figs. 5 and 6 display the evolution of the laminar windward boundary layer at $\mathrm{Re}_{\infty} / \mathrm{ft}=1$ $\mathrm{x} 10^{6}$ to the transitional/turbulent state observed at $\mathrm{Re}_{\infty} / \mathrm{ft}=8 \times 10^{6}$. As expected, boundary-layer transition first appeared at the aft end of the model and was found to move forward with increasing Reynolds number. The transition onset Reynolds numbers should not be applied directly to flight due primarily to the adverse effect of tunnel noise and inherent surface roughness of the phosphor coated ceramic models (which may be different than that found on the metallic surface of the flight vehicle ${ }^{27,28}$ ).

Consistent with earlier observations ${ }^{7}$ made on an X-33 D-loft (603B1001D) forebody, distinctive patterns of the transition front are observed with angle of attack. Fig. 8 a-c illustrates the significant differences found at $\alpha=20,30$, and $40 \mathrm{deg}$ angles of attack at a constant unit Reynolds number of $8 \times 10^{6}$. At $\alpha=20$ deg (Fig. 8a) two transition fronts symmetric about the centerline are observed. As incidence angle is increased, the fronts merge (Fig. $8 \mathrm{~b})$ and eventually coalesce into a single parabolic shape at $\alpha=40 \mathrm{deg}$ (Fig. 8c). The corresponding experimental surface streamline patterns, Fig. 9a-c, indicate boundary layer inflow towards the model centerline at $\alpha=20 \mathrm{deg}$. The inflow of surface streamlines, Fig. 9a, results in a flow convergence on the windward centerline, which would thicken the 
boundary layer locally. The degree of inflow suggests that crossflow may be the mechanism responsible for transition at lower incidence angles. By increasing the sensitivity of the color scale (not shown) the presence of heating striation patterns at low incidence angles was revealed. It is believed that an array of streamwise-orientated boundary layer vortices exist on the windward surface and reveal themselves through local increases in surface shear and thus heating. This vortex formation is believed to be indicative of the onset of three-dimensional, crossflow-induced transition from laminar to turbulent flow. The appearance of heating striatia from vortices entrained within supersonic/hypersonic boundary layers has been inferred from flight measurements as well as observations in hypersonic wind tunnels; the reader is referred to ref. 29 for a more complete review of this phenomenon.

Asymmetric boundary layer transition on the windward surface chine in the vicinity of the fin/body junction was observed on a few isolated occasions during the test series (see Fig. 8b). This transition was attributed to (unintentional) isolated surface roughness in the phosphor coating created from the impacts of small particulates (of less than 5 microns) on the ceramic model. Although this observation initially suggested heightened sensitivity of the chine to transition, a correlation of isolated roughness data revealed that the off-centerline locations were no more sensitive than those on centerline (see ref. 8).

Windward Body Flap

Body flap deflections of 0,10 , and $20 \mathrm{deg}$ were tested to cover the anticipated deflection range. The flow features and resulting surface heating on the deflected flaps was complex and was in large part determined by the extent of boundary layer separation ahead of the flap and subsequent flow reattachment. In turn, the control surface flow separation was largely determined by the state of the boundary layer approaching the flaps. As inferred from the $\alpha=40$ deg surface heating patterns in Fig. 5a-c, the flow leading up to the deflected control surface is laminar (as transition is limited to the center region only) and appears to separate ahead of the flap hinge line (the cooler region upstream of the hingeline). The off centerline transition found at the higher Reynolds numbers for $\alpha=20 \mathrm{deg}$, Fig. 6b-d, reduces or nearly eliminates this separated region.

At low Reynolds numbers, however, the laminar separation bubble at the flap hinge line persists. The surface streamlines associated with laminar separation at $\mathrm{Re}_{\infty} / \mathrm{ft}=2 \times 10^{6}$ from $\delta_{\mathrm{BF}}=20$ deg is shown, Fig. 10a-c, for $\alpha=20,30$, and $40 \mathrm{deg}$. This flow separation bubble becomes smaller with increasing angle of attack. The circulation of separated flow upstream of reattachment was highly three-dimensional with a strong curvature of the streamlines away from the body flap centerline. This outboard directed flow spillage did not appear to influence the flow over the nearby canted fin (as was observed on several X-33 phase I configurations). The flow reattachment downstream on the body flap was observed to be in close proximity and nearly parallel to the hinge line at all angles of attack suggesting locally higher heating in this area. The body flap hinge line gap is planned to be sealed to prevent the circulation of this high energy flow into a cavity. Expansion of the flow around the body flap edges is indicated by the local streamline curvature; the outboard curvature is most pronounced at $\alpha=40$ deg and is indicative of a stronger lateral pressure gradient at the higher angles of attack.

A 20 deg deflected body flap at angles of attack of 30 and 40 deg produced a disturbance in the flap streamline pattern, Fig. 10b-c. Computational predictions of the corresponding flowfield (not presented) indicated the interaction of the deflected flap shock with the bow shock. The outboard location of the X-33 body flaps (in contrast, for example, to the shuttle orbiter body flap) locates the body flap shock system in close proximity to the bow shock. Computed flow field results show that the resulting interaction produced an expansion fan that impinged on the body flap in the same spatial orientation as seen in the experimental heating (Fig 5a) and surface streamline patterns (Fig. 10b-c). A typical side view schlieren image, Fig. 11, at $\alpha=30 \mathrm{deg}, \delta_{\mathrm{BF}}=20 \mathrm{deg}$, and $\mathrm{Re}_{\infty} / \mathrm{ft}=2 \times 10^{6}$ is presented to characterize the shock system in this region. The sensitivity of the schlieren system did not permit the detection of the expansion wave disturbance. This type of surface disturbance on the flap had not been observed on earlier X-33 configurations due to shorter length body flaps. Localized increases in body flap surface heating corresponding to flow reattachment near the hingeline and from the expansion fan disturbance were observed, Fig. 5a, and will be discussed in more detail at a later point. The local heating peak from the disturbance was observed at all Reynolds numbers but because the color bar scale for this report was set to provide the best sensitivity for presentation of windward surface transition images (on the fuselage), the body flap data is off-scale.

In order to provide heating trends on the flaps in the absence of separation, the entire flap surface heating was averaged and presented, Fig. 12, as a function of Reynolds number for an undeflected body flap $\left(\delta_{\mathrm{BF}}=0 \mathrm{deg}\right)$. As expected, the flap surface heating increased with angle of attack. At $\alpha=30$ and $40 \mathrm{deg}$ the averaged heating to the undeflected flap did not vary with Reynolds number suggesting laminar flow. The off centerline transition noted earlier at $\alpha$ $=20 \mathrm{deg}$ is responsible for the increase in the averaged flap heating observed at $\mathrm{Re}_{\infty} / \mathrm{ft}=4 \times 10^{6}$. 
The effect of control surface deflections on averaged flap surface heating is shown Fig. 13a and b. The figures present data obtained with a laminar (Fig. 13a) and turbulent (Fig. 13b) boundary layer approaching the flap (details of the boundary layer tripping method can be found in refs. 9 and 21). The averaged flap heating has been normalized to the measured average with $\delta_{\mathrm{BF}}=0$ deg so as to present heating amplification factors above undeflected levels (in each figure, the undeflected flap reference heating was obtained for both laminar and turbulent conditions). Presented in this fashion, these heating amplifications may be used with analytic solutions with $\delta_{\mathrm{BF}}=0$ deg to provide an estimate of what might be expected in flight. For an approaching laminar boundary layer (Fig. 13a), maximum heating augmentation (i.e. for $\delta_{\mathrm{BF}}=20 \mathrm{deg}$ ) above laminar undeflected flap levels are 7.5 and 5.3 for 30 and 40 deg angles of attack. The amplification levels are reduced by approximately 50\% when the flap heating is normalized to turbulent undeflected flap heating. The effect of tripping the boundary layer approaching the deflected flap has little effect on the averaged deflected flap heating augmentation factors. This suggests that the boundary layer downstream of reattachment is transitional/turbulent.

While the averaged body flap heating was useful to examine trends, the local flow on the deflected flaps was observed to be quite complex. With the exception of the lowest Reynolds numbers, the heating levels found on the deflected body flaps generally meet or exceed the theoretical reference stagnation level $\left(\mathrm{h}_{\mathrm{FR}}\right)$. Right and left body flap centerline heating distributions extracted from images taken at $\alpha=40 \mathrm{deg}, \delta_{\mathrm{BF}}=20 \mathrm{deg}$, and $\mathrm{Re}_{\infty} / \mathrm{ft}=2 \mathrm{x}$ $10^{6}$ are shown, Fig. 14, for both a laminar and turbulent (tripped) boundary layer approaching the flap. For a laminar boundary layer approaching the deflected flap, the local centerline heating peaks from flow reattachment $\left(\mathrm{h} / \mathrm{h}_{\mathrm{FR}}=1.6\right)$ and expansion fan impingement $\left(\mathrm{h} / \mathrm{h}_{\mathrm{FR}}=1.3\right)$ are measured at approximately 5\% and 55\% flap chord length and are spatially consistent with surface oil flow observations. The local heating peak from flow reattachment was reduced nearly $60 \%$ when the boundary layer was tripped upstream of the deflected flap. Based on this observation, it is believed that the tripped boundary layer approaching the flap results in a smaller separation bubble and turbulent reattachment heating levels. The laminar separation yields flow reattachment that is transitional and heating that is characteristically higher than turbulent results. Computations (not shown) suggest the secondary heating peak downstream of reattachment is the result of a thinning boundary layer produced from the head of the expansion wave system impinging on the flap. The rapid decrease in heating downstream of the secondary peak correlates with a predicted drop in surface pressure from the expansion fan tail.

Canted Fin

The shock shape about the X-33 F Rev-F model is shown in planform view, Fig. 15, for $\alpha=$ $30 \mathrm{deg}, \delta_{\mathrm{BF}}=20 \mathrm{deg}$, and $\mathrm{Re}_{\infty} / \mathrm{ft}=2 \times 10^{6}$. The bow shock was observed to interact with the canted fin leading edge at all angles of attack tested. Inherently three-dimensional, the observed shock orientations (inset, Fig. 15) most closely resemble a twodimensional type VI interaction described by Edney ${ }^{30}$ which is known to produce a shear layer and expansion fan. Depending upon model angle of attack, this shear layer is thought to be swept over the fin upper and/or lower surface producing local perturbations in fin surface heating. The surface effect from the shock interaction was not easily discernable from the streamline patterns on the fins (Fig. 9a-c) but was more readily identified in the surface heating images (Fig. 6a-d). The fin windward surface heating resulting from this interaction is complex and more distinct at lower angles of attack. On the canted fin windward surface, elevated heating from boundary layer transition (associated with the bow/fin-shock interaction and possible leading edge attachment line contamination ${ }^{31}$ ) occurs for unit Reynolds numbers in excess of $\mathrm{Re}_{\alpha} / \mathrm{ft}=4 \times 10^{6}$ (Fig. $5 \mathrm{c}-\mathrm{d}$, and 6c-d). Asymmetric boundary layer transition on the windward fin surface was observed on a few isolated occasions during the test series (see Fig. 5c) and was attributed to (unintentional) isolated surface roughness (discussed earlier) on the fin leading edge.

At high angles of attack characteristic of hypersonic entry, the X-33 canted fin lower surface would be exposed to the flow and, in the traditional sense, called a "windward" surface. At low angle of attack representative of ascent, however, this same fin surface would be shadowed from the flow (due to the negative fin incidence). Because of this situation, the fin surfaces in the following section are referred to as "upper" and "lower". Canted fin upper and lower surface heating distributions extracted from images taken at $\alpha=0$ and $30 \mathrm{deg}, \delta_{\mathrm{BF}}=20 \mathrm{deg}$, and $\mathrm{Re}_{\infty} / \mathrm{ft}=$ $4 \times 10^{6}$ are shown, in Fig. 16a-b. The heating distributions were taken at the fin half chord station. At a low incidence angle characteristic of ascent, the surface heating to the canted fin lower surface was less than that measured on the upper fin surface (due to the negative fin incidence). At $\alpha=0 \mathrm{deg}$ (Fig. 16a) the heating to the fin lower surface is relatively uniform at this fin chord location with $\mathrm{h} / \mathrm{h}_{\mathrm{FR}}=0.1$ and with no evidence of locally large increases in surface heating from the bow/fin shock interaction. It is believed the disturbances (shear layer) from the interaction are swept over the fin upper surface producing locally elevated heating. For example, heating to the undisturbed outboard $40 \%$ of the fin 
was found to be near $\mathrm{h} / \mathrm{h}_{\mathrm{FR}}=0.15$ while the disturbed inboard $60 \%$ of the fin had a heating peak of approximately $\mathrm{h} / \mathrm{h}_{\mathrm{FR}}=0.35$. As anticipated, an increase in angle of attack to $30 \mathrm{deg}$, Fig. 16b, produced heating levels on the fin lower surface that are elevated above that measured on the upper surface.

As noted earlier, boundary layer transition associated with the bow/fin-shock interaction occurs for unit Reynolds numbers in excess of $\mathrm{Re}_{\infty} / \mathrm{ft}=4 \mathrm{x}$ $10^{6}$. This is more apparent in the extracted fin heating distributions measured over a range of Reynolds numbers and shown in Fig. 17a-b. The disturbance from the bow shock interaction on the fin lower surface at $\alpha=30 \mathrm{deg}$, Fig. 17a, is not readily discernable at the fin half chord station until $\mathrm{Re}_{\infty} / \mathrm{ft}=$ $4 \times 10^{6}$. Similarly, the transitional effects from the shock interaction on the fin upper surface at $\alpha=0$ deg, Fig. 17b, are not apparent below $\operatorname{Re}_{\infty} / \mathrm{ft}=4 \mathrm{x}$ $10^{6}$.

\section{Engine}

Impingement of the separated flow off the windward fuselage base onto the lower surface of the linear aerospike nozzle was inferred from elevated heating measured at this location (see Fig. 5b-d). Extracted heating distributions at $\alpha=40 \mathrm{deg}$ and $\operatorname{Re}_{\infty} / \mathrm{ft}=4 \times 10^{6}$, Fig. 18, indicated that at reattachment, peak heating was on the order of $\mathrm{h} / \mathrm{h}_{\mathrm{FR}}=$ 0.1 . Surprisingly, support system interference effects (leeside blade mount vs. base sting mount) in this region were not apparent. Flowfield computations at flight conditions also suggest that the boundary layer separating off the body is likely to reattach on the nozzle. In flight, circulating residual hydrogen through the structure during descent will actively cool the nozzle.

\section{Leeward Fuselage}

Much lower heating levels generally characterize the thermal environment of a vehicle leeward surface at hypersonic entry angles of attack. Comparison of leeward centerline heating at $\mathrm{Re}_{\infty} / \mathrm{ft}=$ $2 \times 10^{6}$ and $4 \times 10^{6}$ with laminar prediction $\left(\mathrm{Re}_{\infty} / \mathrm{ft}=\right.$ $4 \times 10^{6}$ ) at $\alpha=40 \mathrm{deg}$ is shown, Fig. 19. The laminar comparison presented here and at lower angles of attack (see ref. 9) was generally within the experimental uncertainty $( \pm 25 \%)$ with the exception near the end of the fuselage. This discrepancy may be due to the fact the model base and wake flow was computationally simplified ${ }^{9}$. The actual flow expansion from the leeside into the wake during the tests might result in the higher heating. No significant Reynolds number effects were observed experimentally which suggests either the leeward flow remained laminar or the difference between laminar and turbulent leeside heating is small. A heating maxima of $7.5 \%$ of the stagnation reference value was measured at $\mathrm{X} / \mathrm{L}=0.2$.
At angles of attack more representative of ascent, the placement of the X-33 TPS split lines in the vicinity of the nosecap becomes more crucial. At low incidence angles, the upper fuselage is effectively a "windward" surface (recall, vehicle peak heating during ascent occurs near Mach 9 corresponding to $\alpha=13 \mathrm{deg}$ ). Laminar centerline heating distributions along the vehicle upper surface at $\mathrm{Re}_{\infty} / \mathrm{ft}=4 \times 10^{6}$ for $\alpha=-5,0,5$, and $10 \mathrm{deg}$ are shown, Fig. 20. These low angle of attack distributions were obtained as a small part of a validation process aimed at determining TPS split lines.

\section{Extrapolation to Flight}

A feature of the phosphor thermography analysis package ${ }^{16}$ (IHEAT) is the ability to extrapolate ground based heating measurements to flight radiation equilibrium wall temperatures. The successful application of this technique to predict flight surface temperatures for both laminar and turbulent conditions was demonstrated in the X-34 program (refs. 16 and 22). Based on the initial success with the X-34 data and the good agreement between the X-33 laminar data and GASP prediction presented in this report, phosphor data were extrapolated to flight surface temperatures and compared to an equilibrium laminar GASP flight prediction, Fig. 21. The tunnel data was obtained at $\alpha=40 \mathrm{deg}, \delta_{\mathrm{BF}}=20 \mathrm{deg}$, and $\operatorname{Re}_{\infty, \mathrm{L}}=2 \times 10^{6}$. Flight conditions at this angle of attack correspond to an altitude of 146,730 ft., velocity of 7,045 ft/s, Mach number of 6.6, and a length Reynolds number of $5 \mathrm{x}$ $10^{6}$. The body flap was omitted for the flight computation. As with the X-34 flight case, no significant real gas effects were anticipated at this $\mathrm{X}$ 33 flight condition. The phosphor images were mapped to the three-dimensional vehicle surface geometry via a new option in the IHEAT code. The global comparison of windward surface temperature presented in Fig. 21 is shown along with data extracted along the centerline. Generally, the surface temperatures compare well over the entire image. The extrapolated wind tunnel data generally compares to within $50 \mathrm{deg} \mathrm{F}$ of prediction along the centerline. This type of information provided to the designer early in the TPS evaluation process would be invaluable and could potentially result in significant savings of computational time required for flight predictions.

\section{Concluding Remarks}

One of the key technologies being demonstrated on the Lockheed Martin X-33 RLV demonstrator is an advanced metallic Thermal Protection System (TPS). The heating environment definition for X-33 incorporates conceptual analysis, ground based testing, and computational fluid dynamics into the TPS design process. This report provides an overview of the hypersonic aeroheating 
wind tunnel program conducted at the NASA Langley Research Center in support of the ground based testing activities. In the past, aeroheating information has significantly lagged behind aerodynamic information due primarily to model and instrumentation complexities associated with aerothermodynamic testing. The X-33 program was able to take advantage of recent developments in a two-color global phosphor thermography technique, providing the first opportunity to conduct an aerothermodynamic screening/trade study concurrent with aerodynamic tests. The work reported herein served as a baseline for a parallel effort to determine the effect of discrete roughness and distributed roughness due to a bowed panel (TPS) array on boundary layer transition (AIAA-99-3560). The study also provided a laminar and turbulent heating database with a wide range of parameters from which engineering and benchmark CFD codes were validated against (AIAA-99-3559).

Global surface heat transfer images, surface streamline patterns, and shock shapes were measured on 0.013 scale (10-in.) ceramic models of the proposed X-33 configuration in Mach 6 air. The test parametrics included angles of attack from -5 to 40 degs, unit Reynolds numbers from $1 \times 10^{6}$ to $8 \times 10^{6} / \mathrm{ft}$, and body flap deflections of 0,10 , and $20 \mathrm{deg}$. Comparisons of the laminar and turbulent experimental data were performed which also served to assess the state of the windward boundary layer. It was determined that natural transition occurred on the windward surface. The smooth body transition patterns observed on the windward surface were strongly dependent on angle of attack and were consistent with early phase II observations (AIAA-980867). At hypersonic entry incidence angles, a complex surface flow environment was observed on the deflected body flaps downstream of reattachment. Experimental and computational results indicated the presence of shock/shock interactions that produced localized heating on the deflected flaps and boundary layer transition on the canted fins. At an incidence angle of $40 \mathrm{deg}$, a laminar boundary layer approaching a 20 deg deflected flap, produced a local heating peak $\left(\mathrm{h} / \mathrm{h}_{\mathrm{FR}}=1.3\right)$ from a shock/shock interaction. Laminar windward centerline heating data from the wind tunnel was extrapolated to flight surface temperatures and generally compared to within $50 \mathrm{deg}$ F of flight prediction.

\section{Acknowledgments}

Without the assistance of the following individuals this work would not have been possible: Mark Cagle, Joe Powers, Mike Powers, Mark Griffith, Ed Covington and Tom Burns for model design/ fabrication/ instrumentation/ surface inspection support; John Ellis, Rhonda Manis, Grace Gleason, Melanie Lawhorne, Harry Stotler, Steve Jones, and Jeff Warner for wind tunnel support;
Sheila Wright and Bert Senter for data acquisition assistance; Bill Wood for CFD analysis support; and, Richard Wheless for documentation assistance. The authors gratefully acknowledge their contributions and behind-the- scenes work.

\section{References}

1.Bekey, I., Powell, R., and Austin. R., "NASA Studies Access to Space," Aerospace America, May 1994, pp. 38-43.

2.Cook, S. A., "X-33 Reusable Launch Vehicle Structural Technologies," AIAA Paper 97-10873, Nov. 1996.

3.Freeman Jr., D. C., Talay, T. A., and Austin, R. E., "Reusable Launch Vehicle Technology Program," AIAA Paper IAF 96-V.4.01, Oct. 1996.

4.Powell, R.W., Lockwood, M.K., and Cook, S. A., "The Road from the NASA Access-to-Space Study to a Reusable Launch Vehicle," AIAA Paper IAF 98-V.4.02, Sept. 1998.

5.Baumgartner, R. I., and Elvin, J. D., "Lifting Body An Innovative RLV Concept," AIAA Paper 95-3531, Sept. 1995.

6.Hamilton, H., Berry, S., Horvath, T., and Weilmuenster, J., "Computational/ Experimental Aeroheating Predictions for X-33 Phase II Vehicle," AIAA Paper 98-0869, January 1998.

7.Thompson. R. A., Hamilton, H. H., Berry, S. A., and Horvath, T. J., "Hypersonic Boundary Layer Transition for X-33 Phase II Vehicle," AIAA Paper 98-0867, January 1998.

8.Berry, S. A.,, Horvath, T. J., Hollis, B.R., Thompson. R. A., Hamilton, H. H., "X-33 Hypersonic Boundary Layer Transition,” AIAA Paper 99-3560, June 1999.

9.Hollis, B.R., Berry, S. A.,, Horvath, T. J., Hamilton, H. H., and Alter, S., "X-33 Computational Aeroheating Predictions and Comparisons with Experimental Data," AIAA Paper 99-3559, June 1999.

10.Miller, C. G., "Langley Hypersonic Aerodynamic/Aerothermodynamic Testing Capabilities - Present and Future," AIAA Paper 901376, June 1990.

11.Reed, R. D. "Wingless Flight The Lifting Body Story," NASA SP-4220, 1997.

12.Barret, C., "Lifting Body Stability and Control," NASA TM -1999-209255, March 1999.

13.Hollis, B.R., Thompson, R. A., Murphy, K., and Nowak, R., "X-33 Aerodynamic/Aerothermodynamic CFD Validation and Flight Predictions," AIAA Paper 99-4163, August 1999.

14.Murphy, K., Nowak, R., Thompson, R. A., and Hollis, B.R., "X-33 Hypersonic Aerodynamic Characteristics," AIAA Paper 99-4162, August 1999. 
15.Buck, G. M., "Automated Thermal Mapping Techniques Using Chromatic Image Analysis," NASA TM 101554, April 1989.

16.Merski, N. R., "Reduction and Analysis of Phosphor Thermography Data With the IHEAT Software Package," AIAA Paper 98-0712, Jan. 1998.

17.Merski, N. R., "Global Aeroheating Wind-Tunnel Measurements Using Improved Two-Color Phosphor Thermography Method" Journal of Spacecraft and Rockets, Vol. 36, No. 2, 1998, pp. 160-170.

18.Reaser, S., Private Communication, Lockheed Martin Skunkworks, May 1999.

19.Buck, G. M. and Vasquez, P., "An Investment Ceramic Slip-Casting Technique for Net-Form, Precision, Detailed Casting of Ceramic Models," U. S. Patent 5,266,252, November 30, 1993.

20.Berry, S.A., Horvath, T.J., Kowalkowski, M. K., and Liechty, D. S., "X-33 (Rev-F) Aeroheating Results of Test 6770 in NASA Langley 20-Inch Mach 6 Air Tunnel," NASA TM-1999-209122, March 1999.

21.Berry, S. A., Bouslog, S. A., Brauckmann, G. J., and Caram, J. M., "Shuttle Orbiter Experimental Boundary-Layer Transition Results with Isolated Roughness," Journal of Spacecraft and Rockets, Vol. 35, No. 3, 1998, pp. 241-248.

22.Berry, S. A., Horvath, T. J., DiFulvio, M., Glass, C., and Merski, N. R., "X-34 Experimental Aeroheating at Mach 6 and 10," Journal of Spacecraft and Rockets, Vol. 36, No. 2, 1998, pp. 171-178.

23.Berry, S. A., Horvath, T. J., Roback, V. E., and Williams, G. B., "Results of Aerothermodynamic and Boundary-Layer Transition Testing of 0.0362-Scale X-38 (Rev. 3.1) Vehicle in NASA Langley 20-Inch Mach 6 Tunnel," NASA TM-112857, September 1997.
24.AeroSoft, "GASP Version 3, The General Aerodynamic Simulation Program, Computational Flow Analysis Software for the Scientist and Engineer, User's Manual," AeroSoft, Inc., Blacksburg, VA., May 1996.

25.Olynick, D. R., and Tam, T., "Trajectory Based Validation of the Shuttle Heating Environment," Journal of Spacecraft and Rockets, Vol. 34, No. 2, 1997, pp. 172-181.

26.Fay, J. A., and Riddell, F. R., "Theory of Stagnation Point Heat Transfer in Dissociated Air," Journal of Aeronautical Sciences, Vol. 25, No. 2, 1958.

27.Bouslog. S.A., Moore, B., Lawson, I., and Sawyer, J. W., "X-33 Metallic TPS Tests in NASA-LaRC High Temperature Tunnel," AIAA Paper 99-1045, Jan. 1999.

28.Palmer, G., Kontinos, D., and Sherman, B., "Surface Heating Effects of X-33 Vehicle TPS Panel Bowing, Steps, and Gaps," AIAA Paper 98-0865, Jan. 1998.

29.Horvath, T. J., Rhode, M. N., and Buck, G. M., "Aerothermodynamic Measurements on a Proposed Assured Crew Return Vehicle (ACRV) Lifting Body Configuration at Mach 6 and 10 in Air," AIAA Paper 90-1744, June 1990.

30.Edney, B., "Anomalous Heat Transfer and Pressure Distributions on Blunt Bodies at Hypersonic Speeds in the Presence of an Impinging Shock," The Aeronautical Research Institute of Sweden, Report 115, 1968.

31.Poll, D.I.A., "A New Hypothesis for Transition on the Windward Face of the Space Shuttle," Journal of Spacecraft and Rockets, Vol. 23, No. 6, 1986, pp. 605-611.

Table 1: X-33 Phase II Aeroheating Tests in NASA LaRC AB Tunnels

\begin{tabular}{|c|c|c|c|c|c|}
\hline Year & Tunnel & Test & Occupancy Dates & Runs & Description \\
\hline 1996 & 20"M6 & 6731 & Aug $28-$ Sept & $1-46$ & D-loft Forebody Baseline \\
\hline 1996 & M6 CF4 & 114 & Oct $17-$ Nov 6 & $1-43$ & Yaw Dispersions \\
\hline 1996 & 20"M6 & 6737 & Dec 6 - Dec 20 & $1-174$ & D-loft Forebody Transition \\
\hline 1997 & $20 " \mathrm{M6}$ & 6751 & June 23 - June 30 & $1-52$ & Generic Bowed Panel Models \\
\hline 1997 & $20 " \mathrm{M6}$ & 6751 & July 15 - July 17 & $52-56$ & Generic Bowed Panel Models \\
\hline 1997 & 20" M6 & 6753 & July 17 - July 22 & $1-22$ & Rev C (37-deg Dihedral) Baseline \\
\hline 1997 & 20" M6 & 6753 & Aug $12-$ Aug 20 & $22-50$ & Rev C (37-deg Dihedral) Baseline \\
\hline 1997 & 20" M6 & 6751 & Aug 27 - Aug 29 & $56-99$ & Generic Bowed Panel Models \\
\hline 1997 & 20"M6 & 6751 & Sept 22 - Sept 24 & $100-115$ & Generic Bowed Panel Models \\
\hline 1997 & 20"M6 & 6763 & Dec 30 - Jan 6 & $1-29$ & Rev F (20-deg Dihedral) Baseline \\
\hline 1998 & $20 " \mathrm{M6}$ & 6763 & Jan $15-\operatorname{Jan} 22$ & $30-68$ & Rev F (20-deg Dihedral) Baseline \\
\hline 1998 & $20 " \mathrm{M6}$ & 6763 & Feb 17 - Mar 4 & $69-203$ & Rev F Discrete Roughness \\
\hline 1998 & 20" M6 & 6769 & Apr 3 - Apr 17 & $1-123$ & Rev F Bowed Panels \\
\hline 1998 & $20 " \mathrm{M6}$ & 6770 & May 22 - Jun 24 & $1-185$ & Rev F Attach-Line Roughness \\
\hline 1998 & 20" M6 & 6777 & Aug 5 - Aug 12 & $1-40$ & Rev F Blade vs. sting \\
\hline 1999 & 20" M6 & 6786 & May 3 - May 14 & $1-84$ & Rev-G Extended Bowed Panels \\
\hline
\end{tabular}



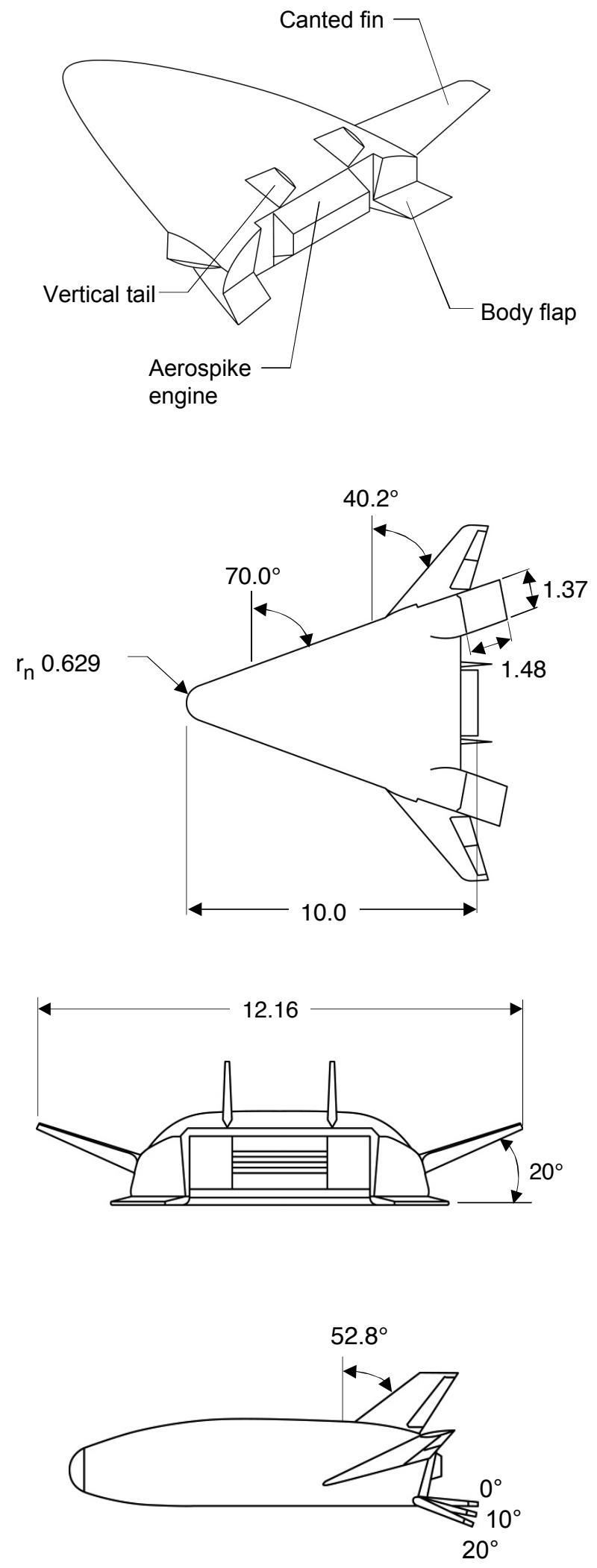

Figure 1. Dimensions (in inches) for 0.013-scale X-33 model of configuration F Rev-F.

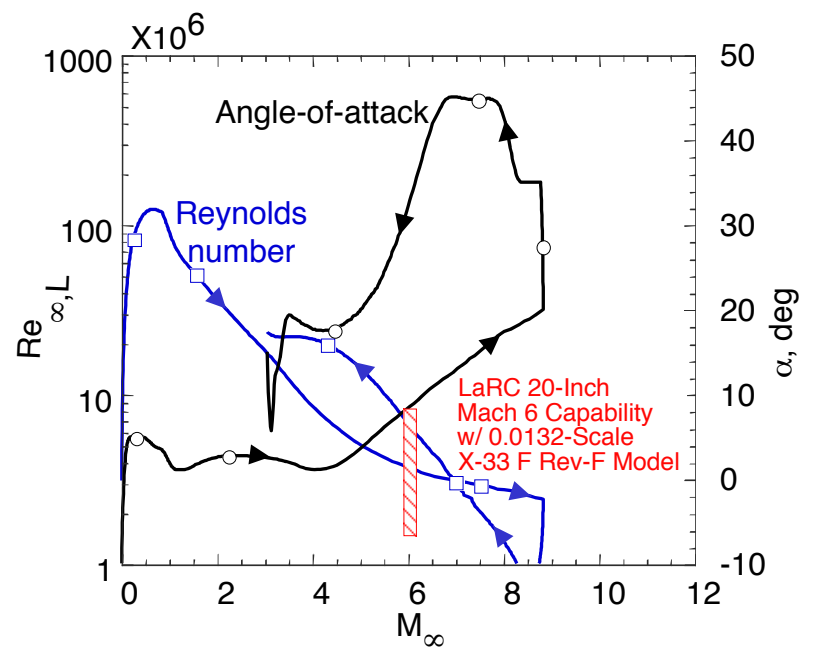

Figure 2. A typical X-33 trajectory.

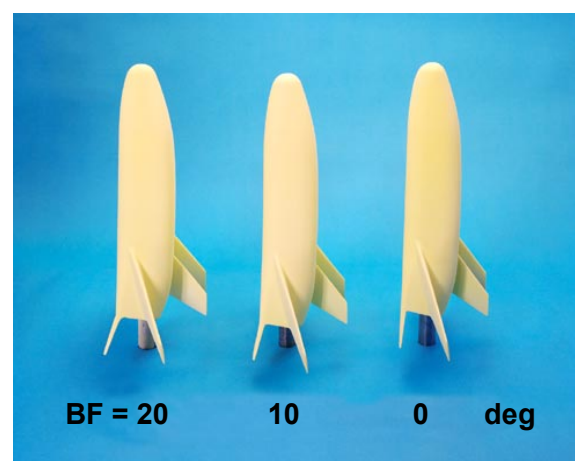

Figure 3. X-33 F Rev-F ceramic models with three flap deflections.

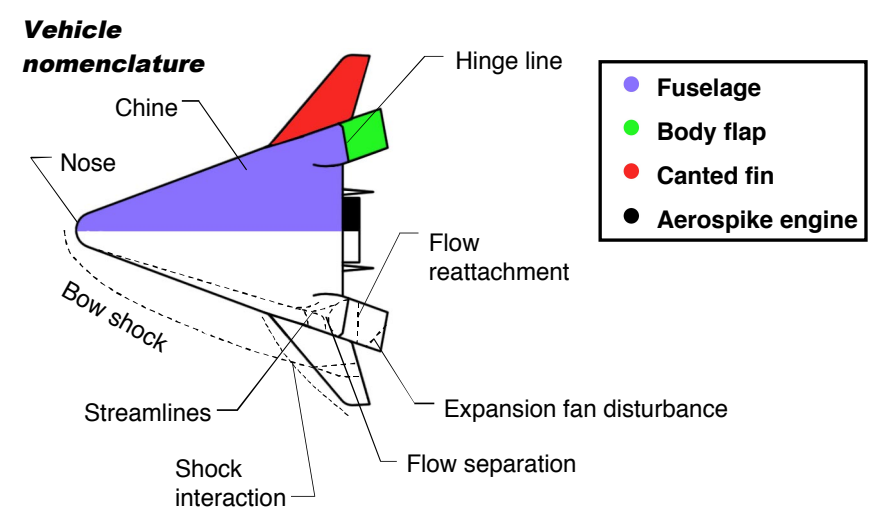

Flow features

Figure 4. X-33 Vehicle nomenclature and flow features. 


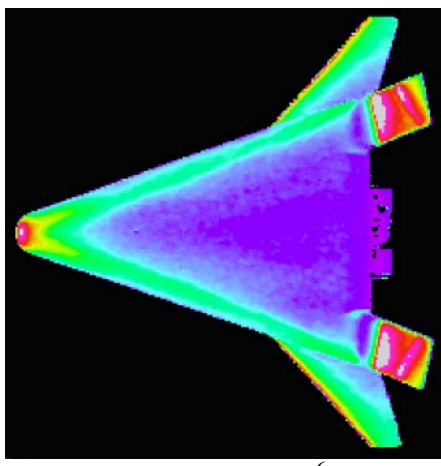

(a) $\operatorname{Re}_{\infty}=1 \times 10^{6} / \mathrm{ft}$

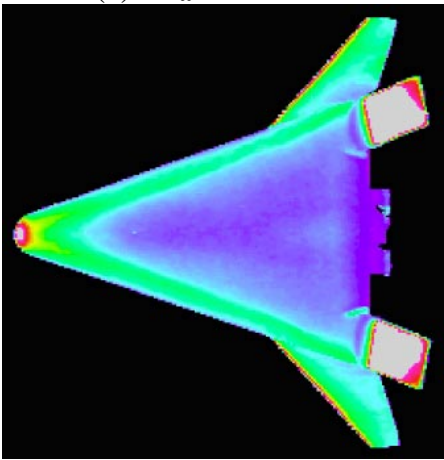

(b) $\operatorname{Re}_{\infty}=4 \times 10^{6} / \mathrm{ft}$

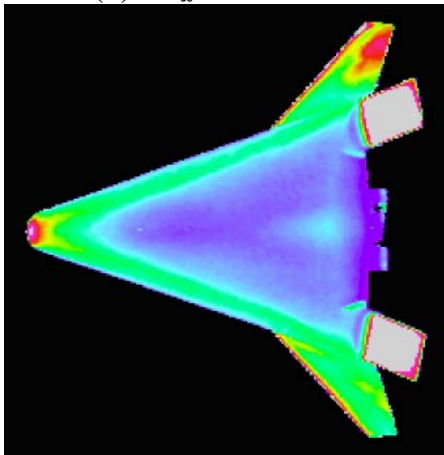

(c) $\operatorname{Re}_{\infty}=6 \times 10^{6} / \mathrm{ft}$

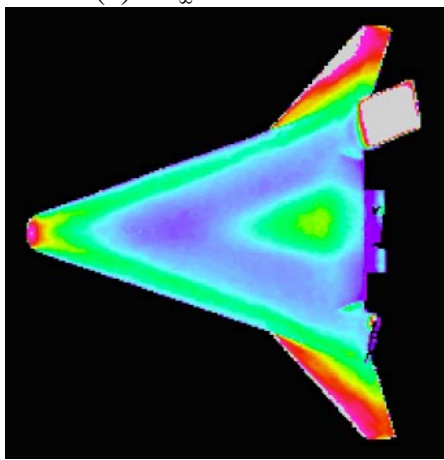

(d) $\operatorname{Re}_{\infty}=8 \times 10^{6} / \mathrm{ft}$

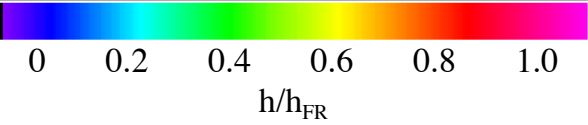

Figure 5. Effect of Reynolds number on windward heating patterns, $\mathrm{M}=6, \alpha=40^{\circ}, \delta_{\mathrm{BF}}=20^{\circ}$.

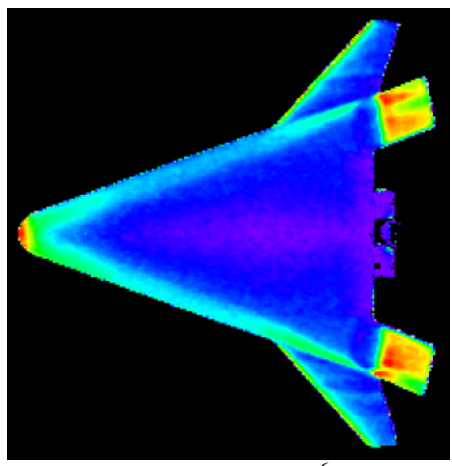

(a) $\operatorname{Re}_{\infty}=1 \times 10^{6} / \mathrm{ft}$

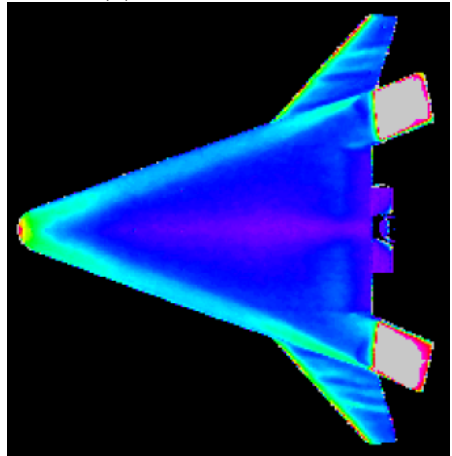

(b) $\operatorname{Re}_{\infty}=4 \times 10^{6} / \mathrm{ft}$

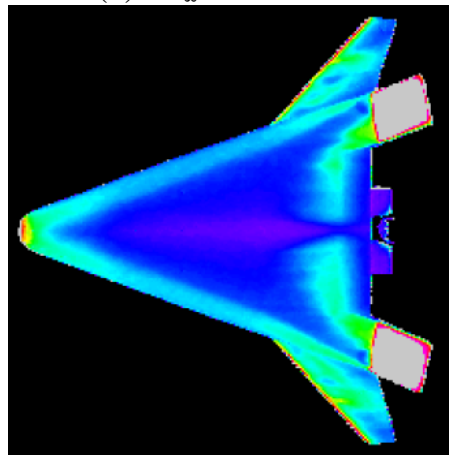

(c) $\operatorname{Re}_{\infty}=6 \times 10^{6} / \mathrm{ft}$

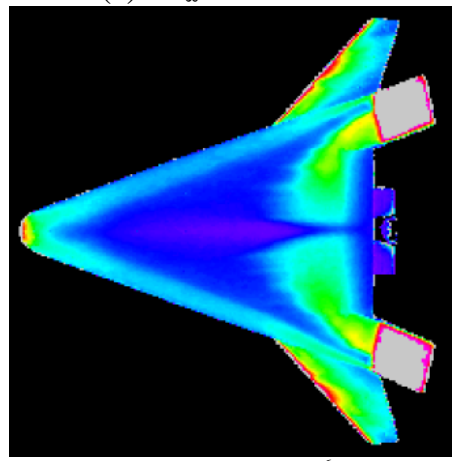

(d) $\operatorname{Re}_{\infty}=8 \times 10^{6} / \mathrm{ft}$

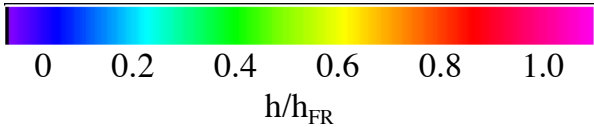

Figure 6. Effect of Reynolds number on windward heating patterns, $\mathrm{M}=6, \alpha=20^{\circ}, \delta_{\mathrm{BF}}=20^{\circ}$. 


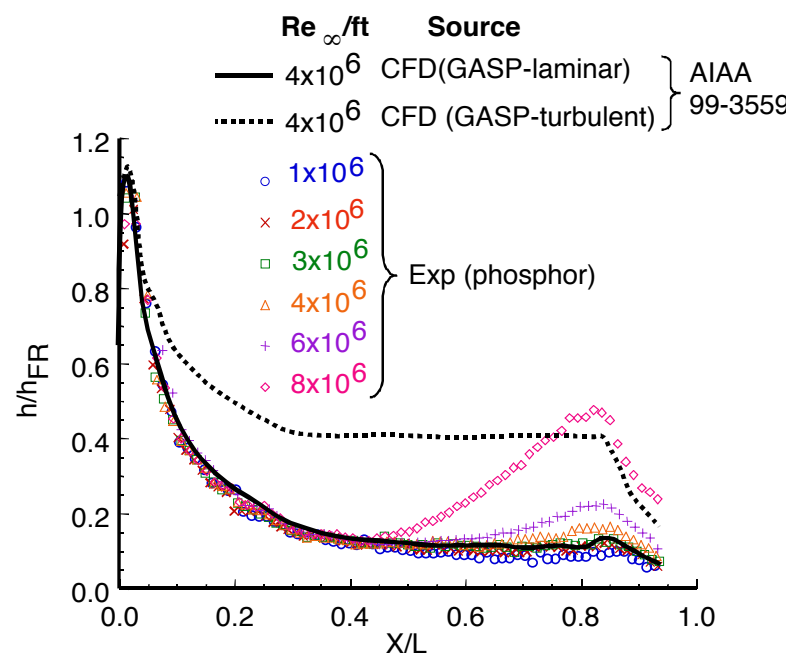

Figure 7. Windward centerline heating comparisons with laminar and turbulent predictions

$$
\mathrm{M}_{\infty}=6, \alpha=40^{\circ} \text {. }
$$

(a) $\alpha=20^{\circ}$

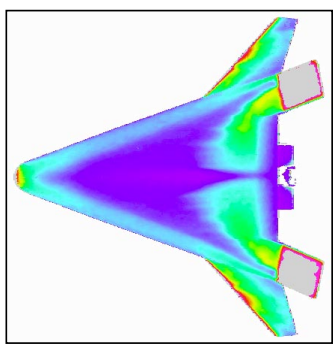

(b) $\alpha=30^{\circ}$

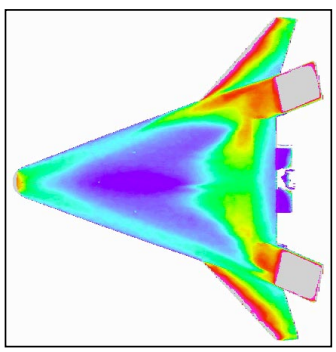

$\mathrm{h} / \mathrm{h}_{\mathrm{FR}}$

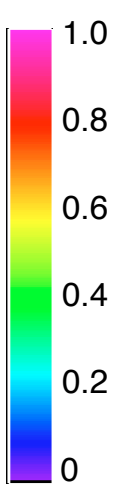

(c) $\alpha=40^{\circ}$

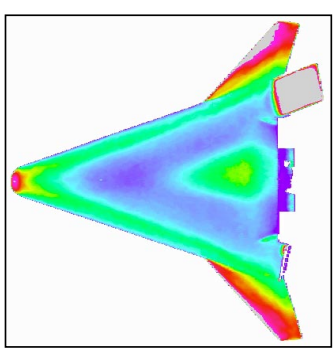

8

6

0.4

0.2

0

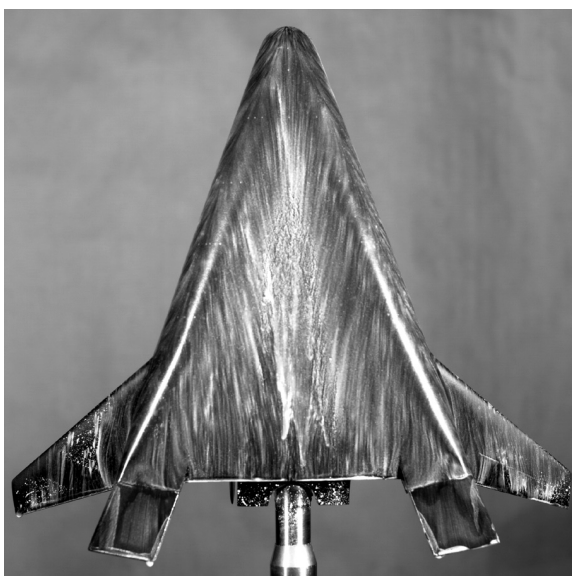

(a) $\alpha=20^{\circ}$

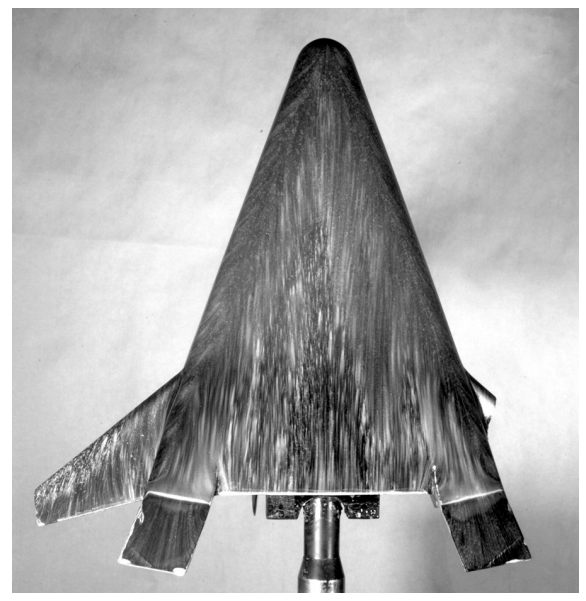

(b) $\alpha=30^{\circ}$

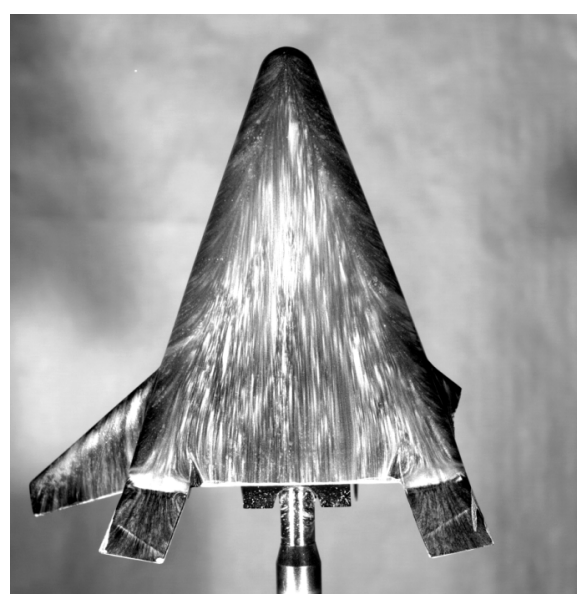

(c) $\alpha=40^{\circ}$

Figure 9. Effect of angle-of-attack on windward surface streamlines

$\mathrm{M}_{\infty}=6, \delta_{\mathrm{BF}}=20^{\circ}, \mathrm{Re}_{\infty}=4 \times 10^{6} / \mathrm{ft}$. 


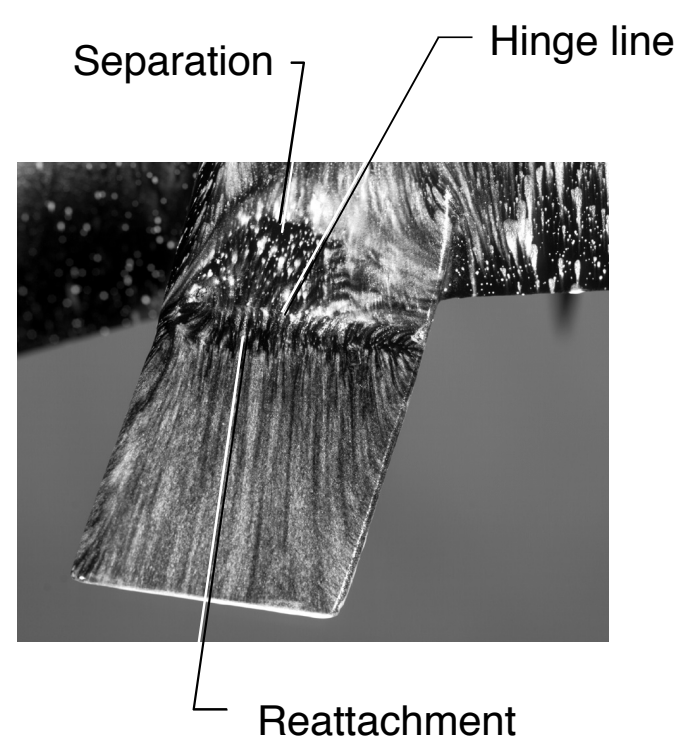

(a) $\alpha=20^{\circ}$

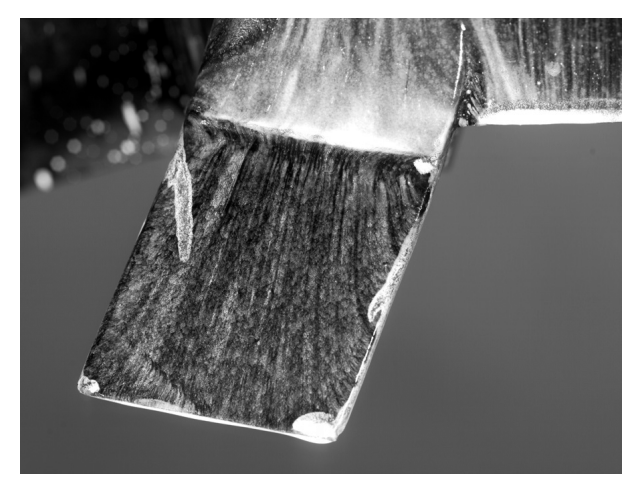

(b) $\alpha=30^{\circ}$

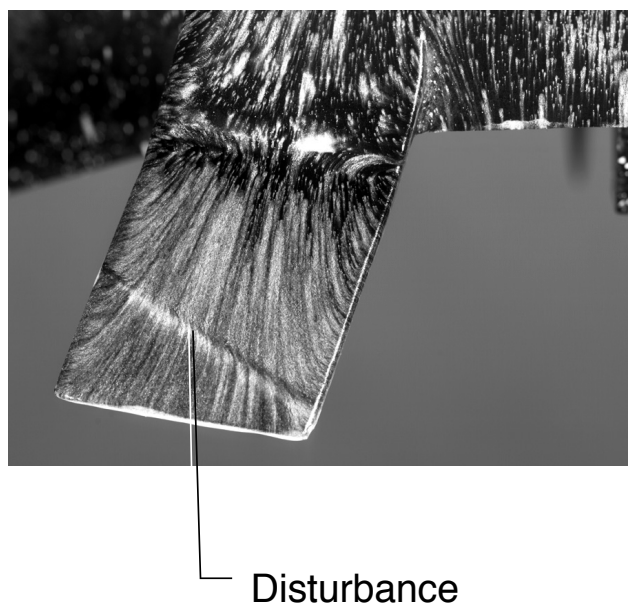

(c) $\alpha=40^{\circ}$

Figure 10. Effect of angle-of-attack on body flap surface streamlines

$$
\mathrm{M}_{\infty}=6, \delta_{\mathrm{BF}}=20^{\circ}, \operatorname{Re}_{\infty}=2 \times 10^{6} / \mathrm{ft} \text {. }
$$

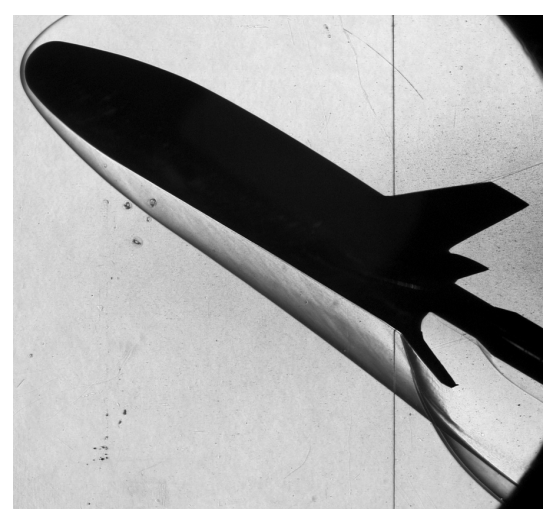

Figure 11. Schlieren image $\mathrm{M}_{\infty}=6, \alpha=30^{\circ}, \delta_{\mathrm{BF}}=20^{\circ}, \operatorname{Re}_{\infty}=2 \times 10^{6} / \mathrm{ft}$.

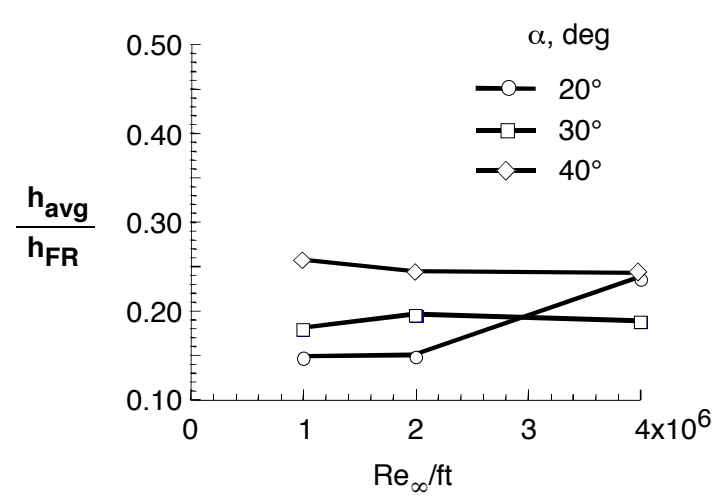

Figure 12. Effect of angle-of-attack and Reynolds number on averaged undeflected body flap heating

$$
\mathrm{M}_{\infty}=6, \delta_{\mathrm{BF}}=0^{\circ}
$$

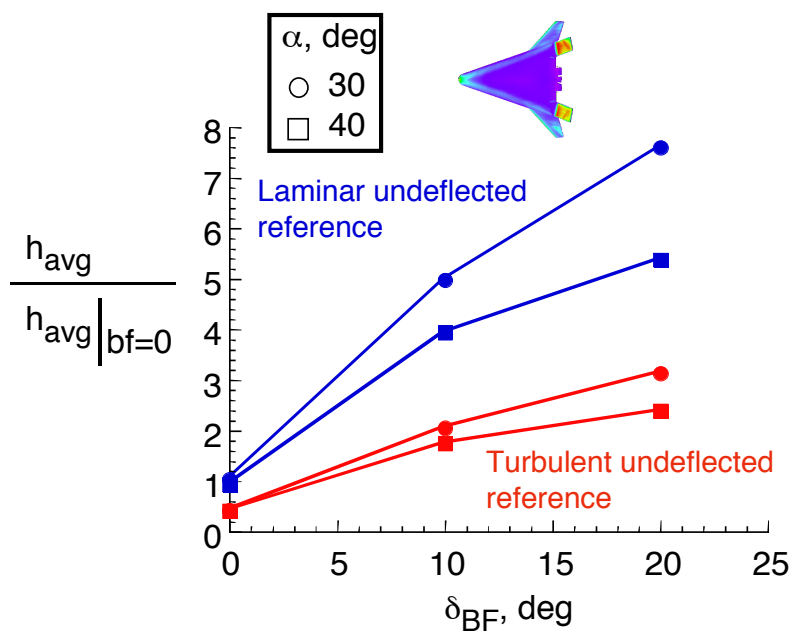

(a) Boundary layer approaching flap: laminar

Figure 13. Averaged deflected body flap heating normalized to laminar and turbulent undeflected reference $\mathrm{M}_{\infty}=6, \mathrm{Re}_{\infty}=4 \times 10^{6} / \mathrm{ft}$. 


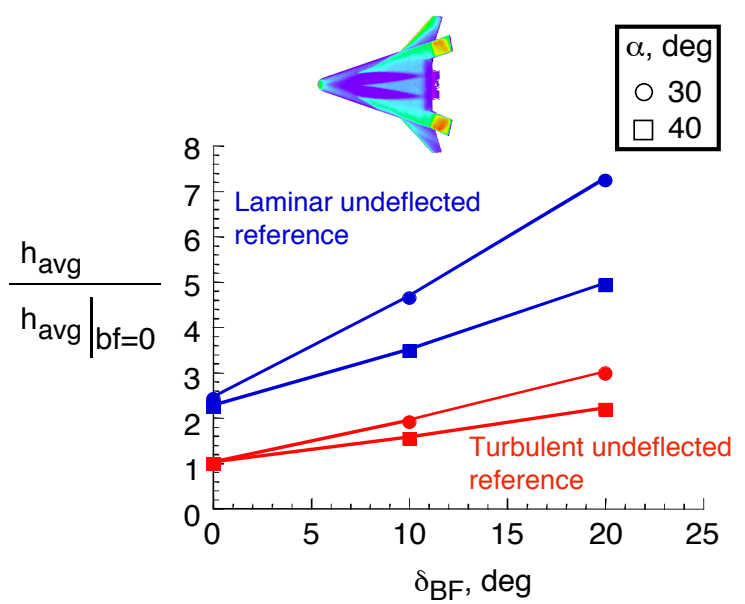

(b) Boundary layer approaching flap: turbulent.

Figure 13. Averaged deflected body flap heating normalized to laminar and turbulent undeflected reference

$$
\mathrm{M}_{\infty}=6, \mathrm{Re}_{\infty}=4 \times 10^{6} / \mathrm{ft} \text {. }
$$

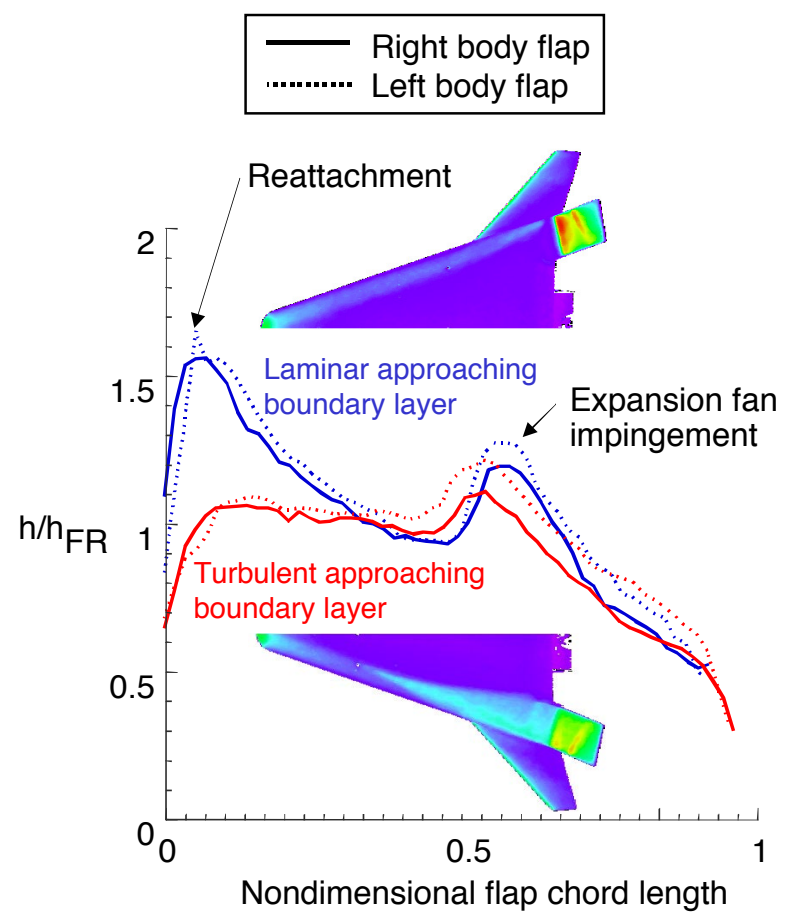

Figure 14. Body flap centerline heating distribution $\mathrm{M}_{\infty}=6, \alpha=40^{\circ}, \delta_{\mathrm{BF}}=20^{\circ}, \operatorname{Re}_{\infty}=2 \times 10^{6} / \mathrm{ft}$.

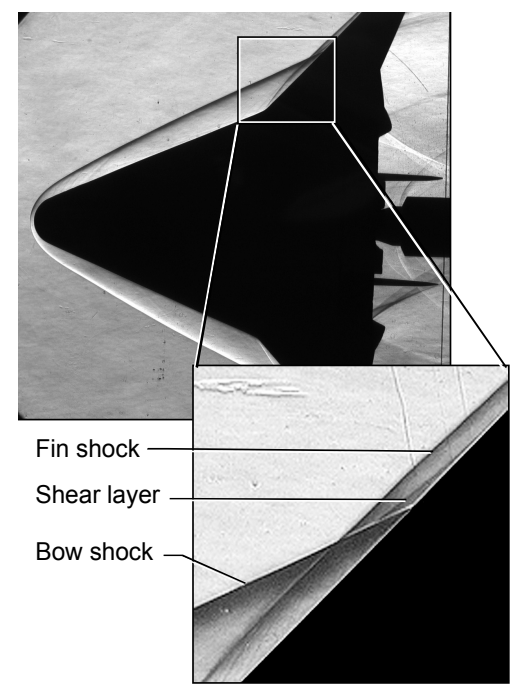

Figure 15. Schlieren image of bow/fin shock interaction $\mathrm{M}_{\infty}=6, \alpha=30^{\circ}, \delta_{\mathrm{BF}}=20^{\circ}, \operatorname{Re}_{\infty}=4 \times 10^{6} / \mathrm{ft}$.

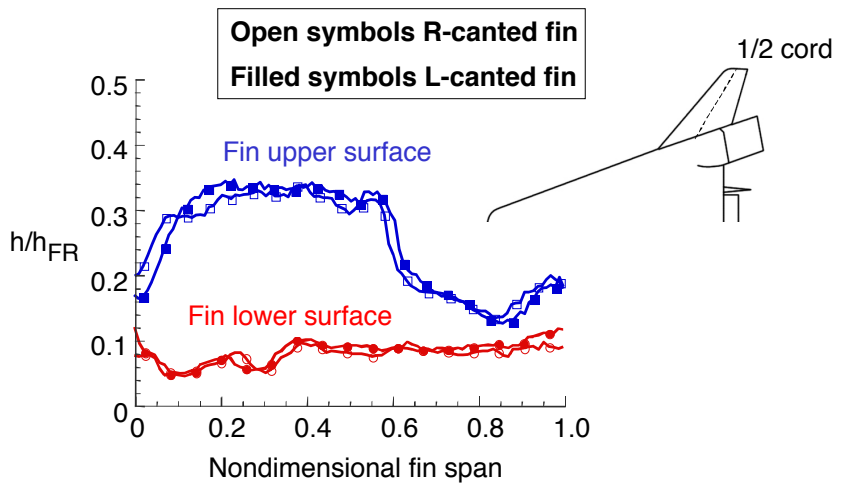

(a) $\alpha=0^{\circ}$

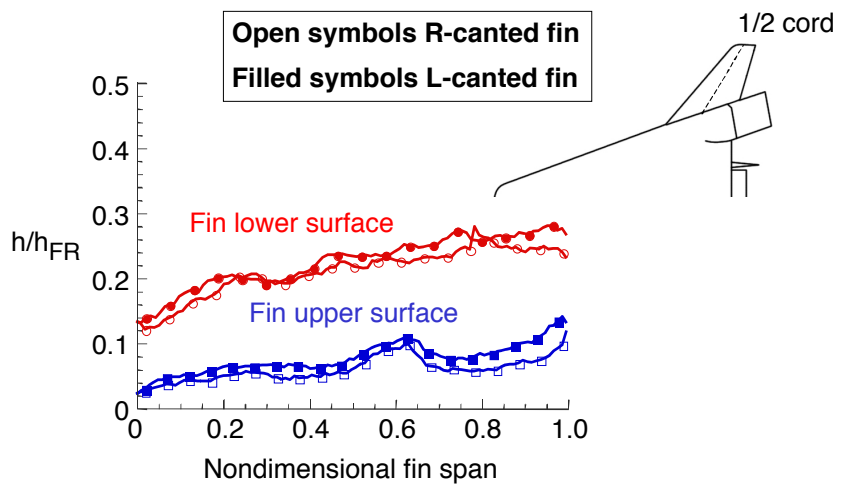

(b) $\alpha=30^{\circ}$

Figure 16. Canted fin heating distribution. $\mathrm{M}_{\infty}=6, \delta_{\mathrm{BF}}=20^{\circ}, \mathrm{Re}_{\infty}=4 \times 10^{6} / \mathrm{ft}$. 


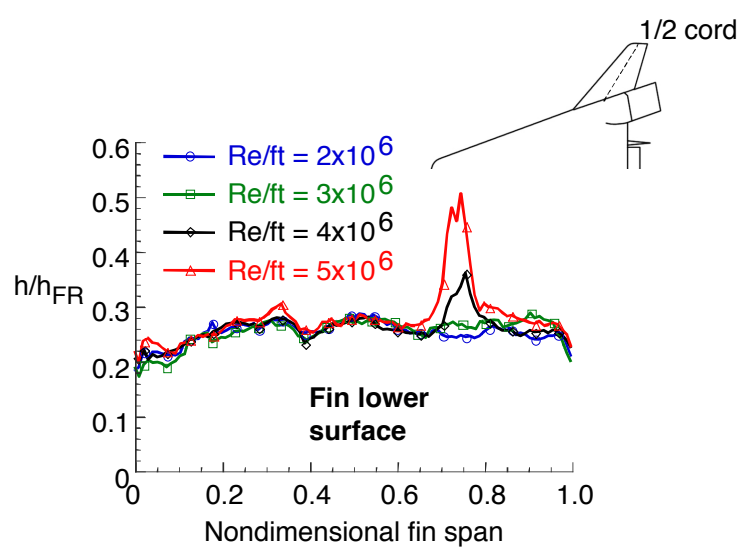

(a) $\alpha=30^{\circ}$

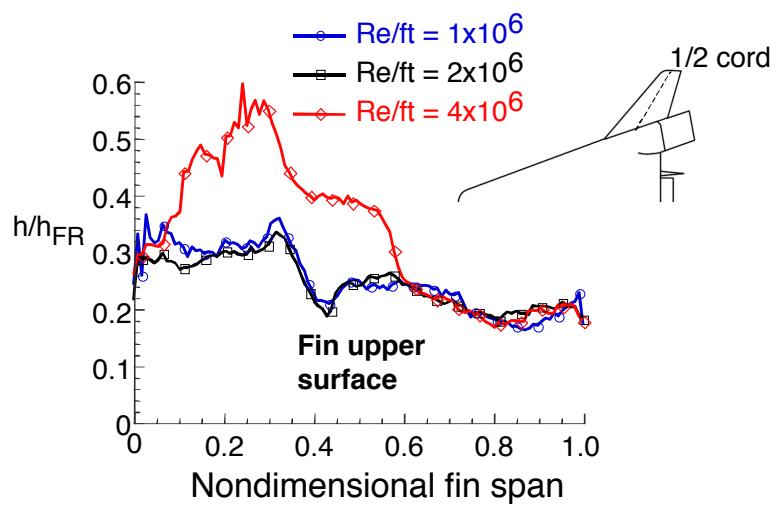

(b) $\alpha=0^{\circ}$

Figure 17. Effect of Reynolds number on canted fin heating distribution $\mathrm{M}_{\infty}=6, \delta_{\mathrm{BF}}=20^{\circ}$.

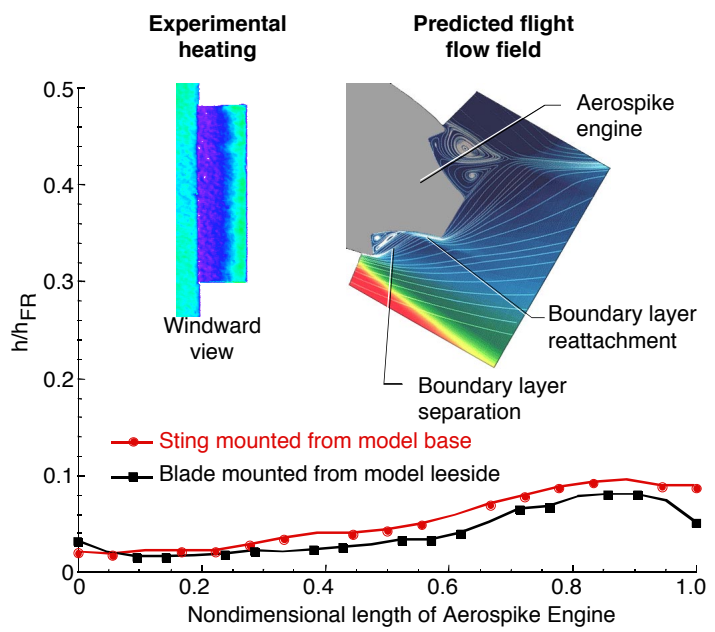

Figure 18. Heating distribution on aerospike engine $\mathrm{M}_{\infty}=6, \alpha=40^{\circ}, \delta_{\mathrm{BF}}=20^{\circ}, \operatorname{Re}_{\infty}=4 \times 10^{6} / \mathrm{ft}$.

(Prediction courtesy K. Weilmuenster) flight; $\alpha=40^{\circ}$

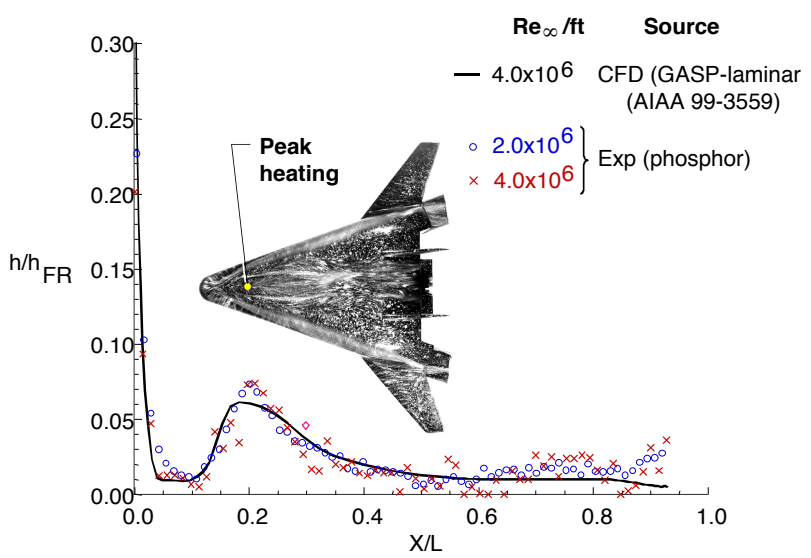

Figure 19. Upper fuselage centerline heating comparison with laminar prediction $\mathrm{M}_{\infty}=6, \alpha=40^{\circ}, \delta_{\mathrm{BF}}=20^{\circ}$.

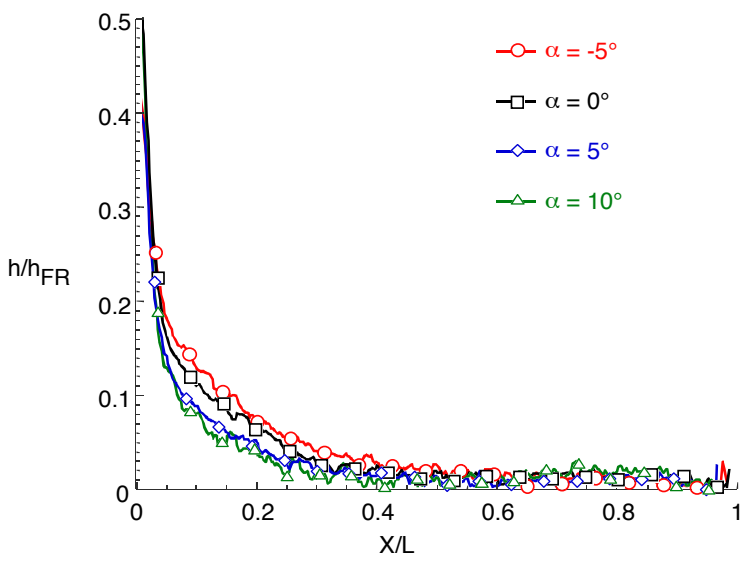

Figure 20. Effect of angle-of-attack on upper fuselage centerline heating distributions $\mathrm{M}_{\infty}=6, \delta_{\mathrm{BF}}=20^{\circ}, \operatorname{Re}_{\infty}=4 \times 10^{6} / \mathrm{ft}$.

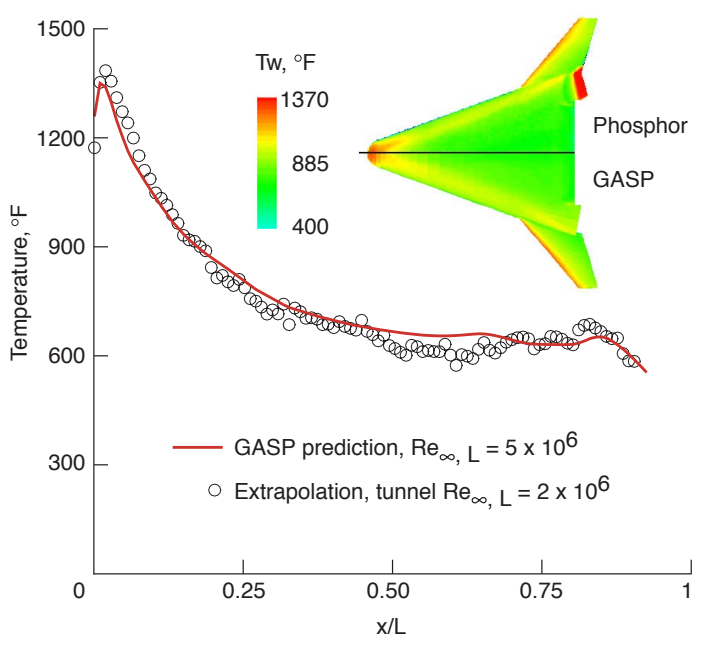

Figure 21. Extrapolation of laminar experimental centerline data to flight conditions $\mathrm{M}_{\infty}=6.6, \alpha=40^{\circ}$. 